\title{
Electrochemical characterization of platinum nanoparticles prepared in water-in-oil microemulsion in the presence of different modifiers and metal precursors
}

\author{
Roberto A. Martínez-Rodríguez ${ }^{[a, b]}$, Francisco J. Vidal-Iglesias ${ }^{[a]}$, José Solla-Gullón ${ }^{[a]}$, Carlos R. \\ Cabrera $^{[\mathrm{b}]}$ and Juan M. Feliu*[a]
}

\begin{abstract}
In this manuscript, Pt nanoparticles have been synthesized using water-in-oil microemulsions in the presence of different modifiers and metal precursors to obtain preferentially oriented nanoparticles. Preferentially oriented cubic nanoparticles, enriched in (100) sites, were mainly prepared for specific concentrations of $\mathrm{HCl}$, $\mathrm{HBr}, \mathrm{H}_{2} \mathrm{SO}_{4}$ and $\mathrm{H}_{3} \mathrm{PO}_{4}$. On the other hand, citric and oxalic acids increased the amount of (111) sites, although not significantly. Nanoparticles have been electrochemically characterised by hydrogen and $\mathrm{Ge}$ ads/desorption processes as well as $\mathrm{CO}$ stripping. Finally, the electrocatalytic activity of the nanoparticles having the highest (100) percentage was evaluated towards ammonia oxidation confirming the electrochemical characterization results. The results obtained indicate that, $15 \% \mathrm{HCl}$-modified $\mathrm{Pt}$ nanoparticles using $\mathrm{K}_{2} \mathrm{PtCl}_{4}$ as metal precursor displayed the highest amount of (100) sites, $46.7 \%$, and gave the highest peak current density for ammonia oxidation, around 5 times that of a polyoriented $\mathrm{Pt}$.
\end{abstract}

\section{Introduction}

The interest towards the synthesis of shape-controlled metallic nanoparticles has rapidly increased over the last years due to their particular properties. Concerning their catalytic and electrocatalytic properties, the control over the shape directs the orientation of the atoms at the surface of the nanoparticles, and thus, the electrocatalytic activity towards many electrocatalytic reactions which are structure sensitive reactions, can be conveniently tuned [1].

In Electrocatalysis, one of the most studied metals is platinum $(\mathrm{Pt})$ due to its interesting catalytic properties over many electrochemical reactions of high interest such as carbon monoxide [2], ammonia [3], methanol [4], ethanol [4c, 5] or formic acid [4b, 6] oxidations and oxygen [7] or nitrite [8] reductions. Interestingly, all of these electrochemical reactions are structure sensitive. Therefore, by controlling the shape of the nanoparticle and thus, their surface structure, remarkable improvements have

[a] Mr. R.A. Martínez-Rodríguez, Dr. F.J. Vidal-Iglesias, Dr. J. SollaGullón, Prof. J.M. Feliu

Institute of Electrochemistry

University of Alicante

Ap. 99, 03080 Alicante (Spain)

E-mail: juan.feliu@ua.es

[b] Prof. C.R. Cabrera

NASA-URC Center for Advanced Nanoscale Materials (CANM),

Department of Chemistry

University of Puerto Rico, Río Piedras Campus

P.O. Box 23346, San Juan 00931-3346, Puerto Rico been reported for carbon monoxide [2b, 2c, 9], ammonia [9-10] or methanol [4b, 11] oxidations and oxygen reduction [7a] among others. In the particular case of the ammonia oxidation in alkaline medium, Pt nanocubes, ideally enclosed by $6(100)$ faces, have shown higher catalytic activity over other kind of Pt nanostructures. This behavior is due to the structure sensitivity to (100) surface planes on which the ammonia oxidation process occurs preferentially [3a, 3b].

The importance of the control over the shape of the nanoparticles has made that a wide variety of methods have been reported to synthesize metallic nanoparticles with well-defined structures. For $\mathrm{Pt}$, there is a plethora of shapes that had been obtained, such as cubes [10b, 10c, 12], tetrahedra [12b] or octahedra [12a] among many others. However, most of these methods require complicated protocols, the need of heat or the use of hazardous materials, making them difficult to be scaled up. From an industrial point of view, synthesis protocols for electrocatalysts' mass production have to fulfill several requirements, so these have to be fast and easy while, if possible, avoiding the need of heating and of expensive reagents.

In a recent communication, we reported a new methodology to prepare cubic Pt nanoparticles with a high yield using a water-inoil (w/o) microemulsion method [10c]. The formation of the cubic $\mathrm{Pt}$ nanoparticles was achieved by adding $\mathrm{HCl}$ in the aqueous phase of the w/o microemulsion. In that work, a high concentration of $\mathrm{HCl}$ was the key point to modify the shape/surface structure of the nanoparticles. Interestingly a volcano-shaped curve was obtained when correlating the quality of the cubic shape and the amount of $\mathrm{HCl}$, being a $25 \% \mathrm{HCl}$ the optimum concentration. In a similar way, $\mathrm{Pt}$ cubes were also obtained by controlling the amount of $\mathrm{H}_{2} \mathrm{SO}_{4}$ added as modifier to the aqueous phase of the w/o microemulsion [10b]. In this latter case, the mean size of the $\mathrm{Pt}$ cubes was relative smaller than that of the $\mathrm{Pt}$ nanocubes synthesized using $\mathrm{HCl}$ as surface modifier. Both methods confirmed that $\mathrm{HCl}$ and $\mathrm{H}_{2} \mathrm{SO}_{4}$ act as surface modifiers and had a control over the surface structure when added in the aqueous phase of the w/o microemulsion. Conversely to other synthesis protocols these do fulfill the above mentioned requirements to be scaled up and applied in industry.

On the other hand, cyclic voltammetry is a powerful tool to characterize the surface orientation of platinum surfaces [13]. For this metal, a voltammogram in $\mathrm{H}_{2} \mathrm{SO}_{4}$ provides direct qualitative information about the surface structure. It is important to recall that it is the surface structure what determines the resulting catalytic activity. In addition some electrochemical reactions such as $\mathrm{Bi}$ and $\mathrm{Ge}$ irreversible adsorptions can be used to measure the amount of sites from nanoparticles with an orientation (111) and (100), respectively, based on previous calibrations performed with 
well-defined surfaces (single crystals) [13]. Unlike Transmission Electron Microscopy (TEM) where only a small number of nanoparticles are studied, cyclic voltammetry provides representative information of the sample. Additionally, it is worth noting that shape is only an indicator of the surface structure but the surface of a nanoparticle can be perturbed without noticing a difference in a regular TEM image [14]. Interestingly, advanced microscopic techniques such as spherical-aberration-corrected transmission electron microscopy, can be used to provide atomicresolution information about the local topologies of active sites [15]. Unfortunately, this type of analysis is still quite unusual, very time consuming, again statistically unrepresentative as a limited number of nanoparticles is analysed and obviously, requires very expensive instrumentation not easily available.

The present manuscript extends the study of the effect of the presence of different surface modifiers towards the synthesis of shaped Pt nanoparticles, mainly cubes, also covering the effect of using different metal precursors. In all cases, the surface modifiers have been incorporated to the water phase of the w/o microemulsion. The synthesized Pt nanoparticles have been characterized by TEM and also electrochemically using the socalled hydrogen adsorption/desorption process and germanium irreversible adsorption to quantify the amount of (100) sites. CO stripping and ammonia electrooxidations have been also studied as test reactions in order to determine the catalytic activity.

\section{Results and Discussion}

As previously indicated in the introduction, we recently reported the synthesis of $\mathrm{Pt}$ nanocubes with a very high yield by adding $\mathrm{HCl}$ into the aqueous phase of the w/o microemulsion. In that manuscript the concentration of $\mathrm{HCl}$ used ranged from 0 to $37 \%$ and the optimum for the preparation of those shaped nanoparticles was located at $25 \%$. Nevertheless, the effect of other hydrogen halides was not evaluated. Thus, first of all, the effect on the shape of the $\mathrm{Pt}$ nanoparticles using $\mathrm{HBr}$ and $\mathrm{HI}$ has been also evaluated.

The first modifier to be evaluated was bromhydric acid. $\mathrm{HBr}$ has been previously reported to selectively adsorb onto $\{100\}$ facets of Pd nanocrystals [16]. This selective adsorption stabilizes these facets during the growth of the nanoparticles and then $\mathrm{Pd}$ nanocubes, which are enclosed by six $\{100\}$ facets, are obtained [17]. Figure $1 \mathrm{~A}$ shows a collection of the positive scans of the $\mathrm{CV}$ response for $\mathrm{Pt}$ nanoparticles prepared with different concentrations of $\mathrm{HBr}$ in the water phase of the w/o microemulsion. As usual, the voltammetric profile of a platinum surface in a $0.5 \mathrm{M} \mathrm{H}_{2} \mathrm{SO}_{4}$ solution gives us significant information concerning the nature and quantity of the different surface sites. In brief, four different contributions can be observed. These are centred approximately at $0.12,0.27,0.37$ and $0.53 \mathrm{~V}$ vs RHE and are ascribed to the presence of (110) sites, (100) steps and terrace borders, (100) terraces and wide (100) domains and (111) sites, respectively. As it is observed, when increasing the $\mathrm{HBr}$ concentration from 0 to $25 \%$, the contribution due to the (100) terraces remarkably increases, together with the band at $0.27 \mathrm{~V}$ due to (100) steps and terrace borders. In general terms, the increase of both (100)-related contributions comes together with a decrease in the (110) contribution, as well as that due to the (111) sites, although this latter signal is very weak in all cases. Interestingly, as in the case of $\mathrm{HCl}$ as modifier, the maximum for (100) sites is also observed at $25 \%$. After this maximum is reached, increasing amounts of $\mathrm{HBr}$ cause a sudden decrease in the $(100)$ terrace contribution, but not in that due to $(100)$ small sites, which grows even more, unlike the behaviour previously reported when using $\mathrm{HCl}[10 \mathrm{c}]$. In addition, the other two contributions, related to (110) and (111) sites, also grow.

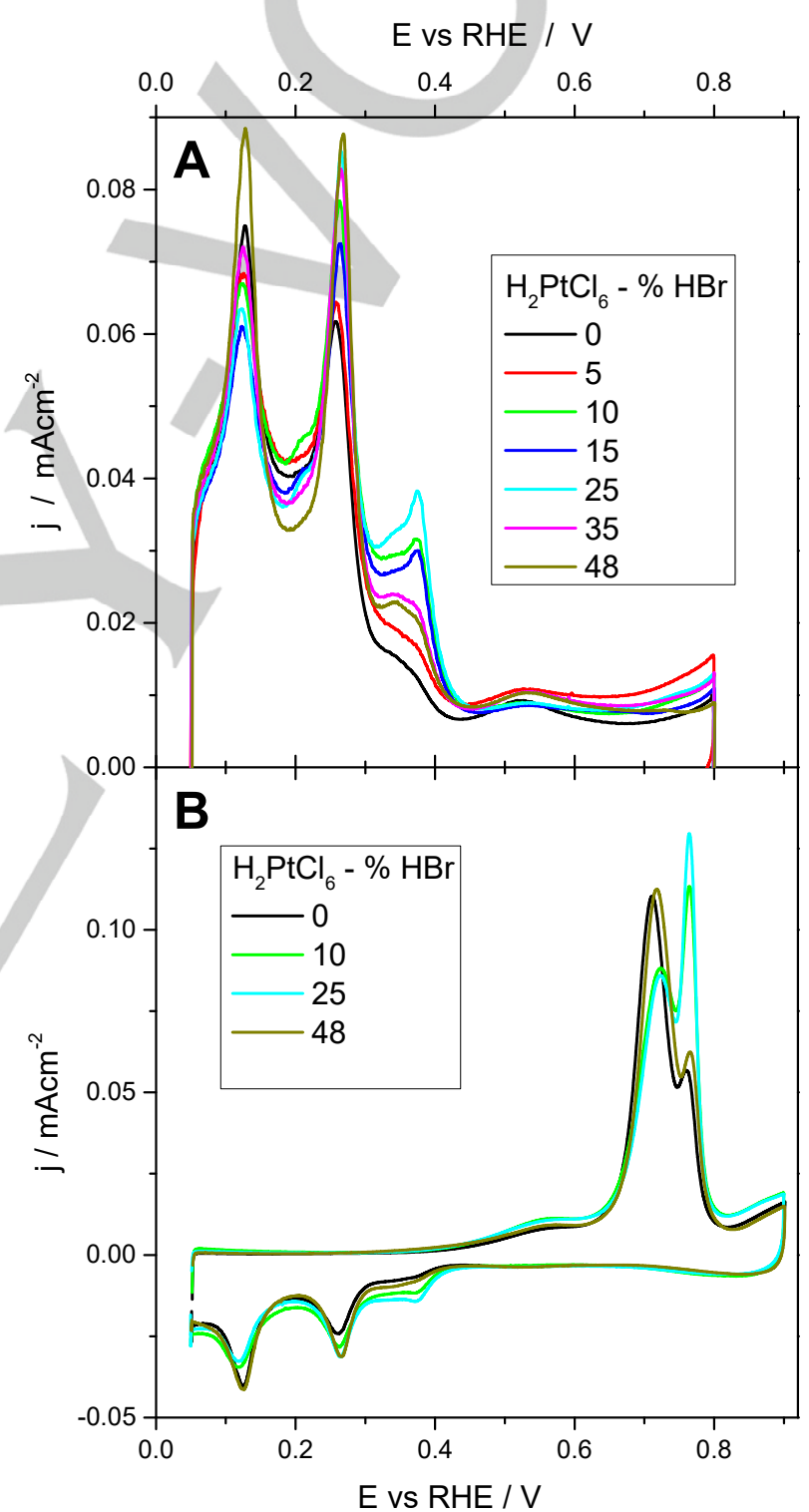

Figure 1. (A) Voltammetric profiles of $\mathrm{Pt}$ nanoparticles synthesized using different concentration of $\mathrm{HBr}$ in the water phase of w/o microemulsions. Scan rate $50 \mathrm{mV} \mathrm{s}^{-1}$. (B) CO monolayer oxidation. Scan rate $20 \mathrm{mV} \mathrm{s}^{-1}$. Test solution $0.5 \mathrm{M} \mathrm{H}_{2} \mathrm{SO}_{4}$. 
Figure 1B shows the $\mathrm{CO}$ stripping oxidation in $\mathrm{H}_{2} \mathrm{SO}_{4}$ for the samples prepared in the presence of $\mathrm{HBr}$. For sake of clarity, only the voltammetric behaviour of some samples is shown. CO stripping is also a structure sensitive reaction, and it has been previously reported the different voltammetric behaviour of different nanoparticles with different surface structures [2c]. In the voltammograms shown in figure $1 \mathrm{~B}$, two different peaks are observed for its oxidation, being centred at 0.73 and $0.78 \mathrm{~V}$, being the latter ascribed to the presence of preferential (100) domains [2c]. In this way the trend observed for the (100) terrace contribution centred at $0.37 \mathrm{~V}$ in $\mathrm{H}_{2} \mathrm{SO}_{4}$ (fig. 1a) is reflected for this $\mathrm{CO}$ contribution, increasing from 0 to $25 \%$ and then decreasing for higher $\mathrm{HBr}$ concentrations in the water phase. Evidently, the increase of the sharp peak is compensated with a decrease of the other voltammetric feature and vice versa.

In this regard, S.G. Sun's group has recently reported that, in the presence of $1 \mathrm{mM} \mathrm{HBr}$, the potential at which the surface oxidation of a $\mathrm{Pt}(100)$ surface starts is shifted to more positive potentials (from 0.6 to $0.9 \mathrm{~V}$ vs RHE [18]) thus reflecting a strong bromide-Pt(100) interaction and concluded that the origin of protecting the long-range ordered (100) structure by $\mathrm{HBr}$ is mainly through the inhibition of oxygen adsorption. The conclusions from that manuscript clearly agree with our finding. Thus, during the growth of the nanoparticles, bromide is adsorbed on the (100) surfaces thus inducing the preferential formation of nanocubes.

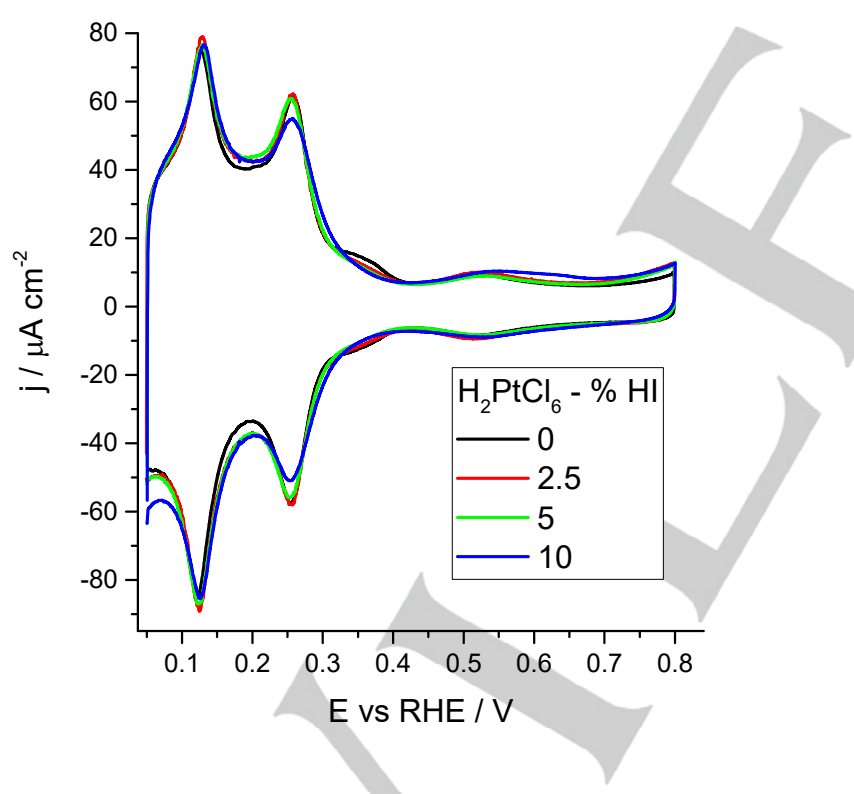

Figure 2. Voltammetric profiles of Pt nanoparticles synthesized using different concentration of $\mathrm{HI}$ in the water phase of w/o microemulsions. Scan rate $50 \mathrm{mV}$ $\mathrm{s}^{-1}$. Test solution $0.5 \mathrm{M} \mathrm{H}_{2} \mathrm{SO}_{4}$.

With the same objective, the effect of the addition of different concentrations of $\mathrm{HI}$ up to $10 \% \mathrm{w} / \mathrm{w}$ has been also explored. However, for $10 \%$ or higher $\mathrm{HI}$ amounts, the platinum precursor was not completely reduced while working in the same experimental conditions as those used throughout the manuscript for all the syntheses. Figure 2 shows the voltammograms in $\mathrm{H}_{2} \mathrm{SO}_{4}$ of the nanoparticles prepared in the absence and presence of $\mathrm{HI}$ in the water phase of the microemulsion. The voltammetric profiles indicate a clear diminution of both (100) step and terrace contributions with increasing amounts of $\mathrm{HI}$. In this case, the lower concentration has been reduced to $2.5 \%$, giving similar results in comparison with the $5 \%$ and $10 \%$. In fact, the voltammograms recorded for the 3 types of nanoparticles prepared in the presence of $\mathrm{HI}$ show the typical profile of a polyoriented platinum surface. Although much lower concentrations have been used for $\mathrm{HI}$ in comparison with $\mathrm{HCl}$ or $\mathrm{HBr}$, the results are nevertheless very clear concerning the lack of any preferential orientation. For both $\mathrm{HCl}$ and $\mathrm{HBr}$ the preferential $(100)$ orientation is very similar and it is also quite clear for a $10 \%$ of the corresponding hydrogen halide, conversely to the effect of $\mathrm{HI}$.

In the case of palladium, the use of $\mathrm{KBr}$ into a polyol system led to the formation of nanocubes and nanobars (enclosed by $\{100\}$ facets) while the use of $\mathrm{KCl}$ had a different effect, cuboctahedra being mainly formed [19]. However, the use of KI resulted in much smaller nanoparticles with poorly defined shape due to the much stronger chemisorption of $\mathrm{I}^{-}$on the nanocrystal surface, being the adsorption strength order $\mathrm{Cl}^{-}<\mathrm{Br}^{-}<\mathrm{I}^{-}[20]$. This result is similar to that observed in our case for platinum nanoparticles. In the case of $\mathrm{HI}$-modified platinum nanoparticles, the mean size is around 5 $\mathrm{nm}$, while in the case when $\mathrm{HCl}$ or $\mathrm{H}_{2} \mathrm{SO}_{4}$ is used as surface modifier, the mean size is significantly higher (about 12-14 nm [10c] and 9 [10b] nm, respectively). Thus, probably l- adsorbs very strongly on all the different orientations and consequently no preferential orientation is observed, which may also explain the smaller size of the nanoparticles prepared in the presence of $\mathrm{HI}$. Besides using hydrogen halides as surface modifiers, $\mathrm{H}_{2} \mathrm{SO}_{4}$ was also reported to cause a preferential (100) orientation in the synthesized nanoparticles [10b], similarly to that shown for $\mathrm{HCl}$ and $\mathrm{HBr}$. In this contribution, a different multiprotic acid was used, but reducing considerably the strength of the acid to analyses its possible effect on the resulting shape/surface structure of the nanoparticles. For this purpose, phosphoric acid was employed. The purity of this acid was $85 \%$ and micellar solution showed good stability and both metal precursor dissolution and chemical reduction reaction could be effectively achieved even at that high acid concentration. The results obtained, figure 3 , show a polyoriented profile for the nanoparticles prepared in the absence of modifier $\left(0 \% \mathrm{H}_{3} \mathrm{PO}_{4}\right)$ which evolves to a slightly preferential (111) voltammogram for increasing $\mathrm{H}_{3} \mathrm{PO}_{4}$ contents up to a $10 \%$. Thus, the contribution at $0.51 \mathrm{~V}$ is maximum at the expense of the two (100) contributions, which diminish. The (110) contribution becomes also lower, but so slightly that its change can be neglected. Nevertheless, if the phosphoric acid concentration is further increased, the (100) signals become progressively more intense up to the maximum $\mathrm{H}_{3} \mathrm{PO}_{4}$ concentration in the water phase, thus showing a clear voltammetric behaviour of preferentially oriented (100) nanoparticles. Together with this (100) increase, from the $10 \%$ to the $85 \% \mathrm{H}_{3} \mathrm{PO}_{4}$, the (110) and (111) contributions diminish. 


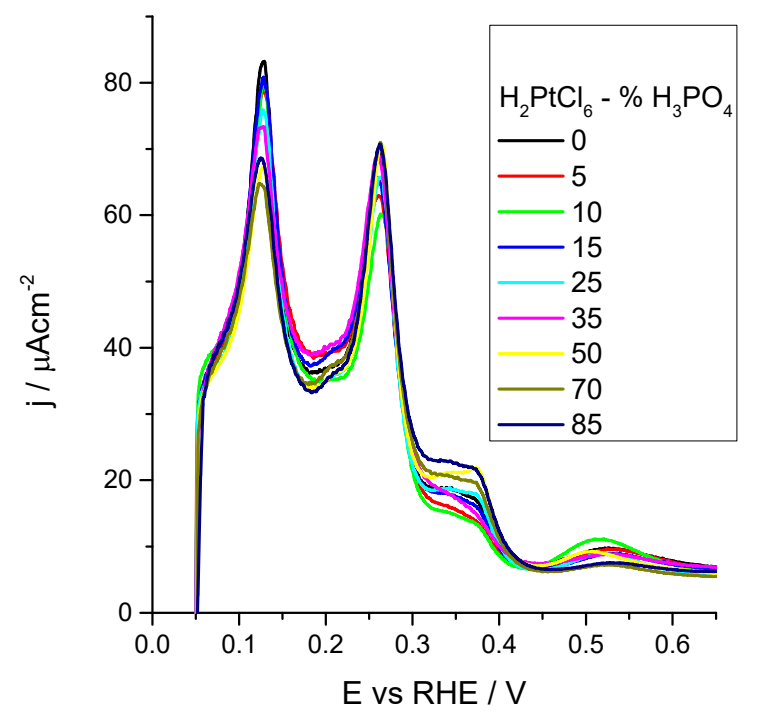

Figure 3. Voltammetric profiles of Pt nanoparticles synthesized using different concentration of $\mathrm{H}_{3} \mathrm{PO}_{4}$ in the water phase of w/o microemulsions. Scan rate 50 $\mathrm{mV} \mathrm{s}^{-1}$. Test solution $0.5 \mathrm{M} \mathrm{H}_{2} \mathrm{SO}_{4}$. cause a moderate increase in the amount of (111) sites, although to a much lower extent. This (111)-site growth comes together with a diminution of the (100)-terrace contribution. The maximum increase of (111) sites is recorded for citric acid, which is in agreement with molecular dynamics simulations performed for $\mathrm{Pd}$, for which the strong interaction of the $\mathrm{OH}$ functional group in the citric acid molecule with the $\operatorname{Pd}(111)$ surface, explains why nanoparticles synthesized in its presence are dominated by (111) facets [25].
Important contributions have been also published in the last years concerning the use of different organic molecules to guide metal crystals to a preferential nanoparticle shape. For example, Chiu et al. reported the preparation of platinum nanoparticles using many different modifiers such as ascorbic acid, catechol, hydroquinone, syringol or resorcinol among others [21]. The authors concluded that negative electrostatic potential on the aromatic ring is prerequisite to display binding selectivity to $\mathrm{Pt}(111)$, while a neutral to positive one prefers $\mathrm{Pt}(100)$. In addition, they claimed that the geometric matching between molecular binding sites and surface lattices plays a role as well in facet selectivity. In addition, Ruan et al. recently studied the synthesis of platinum nanoparticles in the presence of different peptides [22] They observed that those with phenylalanine gave high tetrahedral yields. Similarly but for Pd, Lim et al. reported that citrate or citric acid could selectively stabilize $\{111\}$ facets and thus, favour the formation of $\mathrm{Pd}$ nanocrystals enclosed by $\{111\}$ facets, such as octahedrons [23].

Accordingly, we have evaluated some organic acids at certain concentrations in order to evaluate their effect as surface modifiers. The selection of citric, oxalic and ascorbic acids as modifiers has been made due to the fact that those are well known in the case of Pd for the synthesis of octahedra and cubes [24]. The percentages used for citric acid, ascorbic acid and oxalic acid have been 9,8 and $4 \%$ respectively. These values are in the range of those used in bibliography [23]. The other parameters of synthesis have been the same as in previous experiments.

Figure 4 shows the voltammograms recorded for the different nanoparticles modified with those organic acids. The effect of these modifiers is very small, but as in the case of Pd [23] they

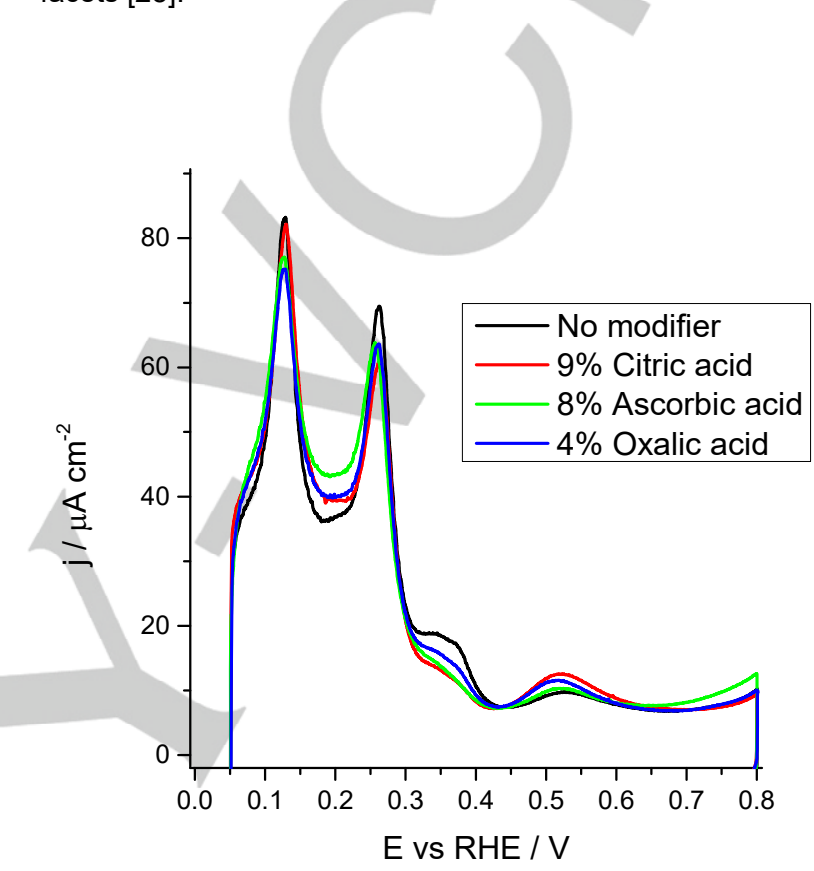

Figure 4. Voltammetric profiles of Pt nanoparticles synthesized using three different organic acids in the water phase of w/o microemulsions. Scan rate 50 $\mathrm{mV} \mathrm{s}^{-1}$. Test solution $0.5 \mathrm{M} \mathrm{H}_{2} \mathrm{SO}_{4}$.

The nanoparticles prepared up to this point as well as those previously reported with this methodology [10b, 10c] have been synthesised using $\mathrm{H}_{2} \mathrm{PtCl}_{6}$ as metal precursor. Consequently, the effect of using a different platinum source has also been analysed. This synthesis was exclusively performed with those modifiers which gave the most satisfactory results with $\mathrm{H}_{2} \mathrm{PtCl}_{6}$ as platinum precursor. Thus, nanoparticles were synthesized using $\mathrm{K}_{2} \mathrm{PtCl}_{4}$ as platinum source in the presence of different concentrations of $\mathrm{HCl}$ and $\mathrm{H}_{2} \mathrm{SO}_{4}$, being their electrochemical characterization shown in figures 5 and 6 , respectively. Figure $5 \mathrm{~A}$ shows the voltammetric profiles in $0.5 \mathrm{M} \mathrm{H}_{2} \mathrm{SO}_{4}$ of the Pt nanoparticles synthesized using $\mathrm{HCl}$ as surface modifier up to a maximum concentration of $20 \%$. An impressive change in the so called hydrogen region is clearly observed when the amount of $\mathrm{HCl}$ used in the synthesis is increased (for sake of comparison, the voltammetric profile of the nanoparticles synthesized with $\mathrm{K}_{2} \mathrm{PtCl}_{4}$ in the absence of $\mathrm{HCl}$ is also plotted). The relative increase of the peaks at 0.27 and especially at $0.37 \mathrm{~V}$ vs RHE denotes a clear change in the surface structure produced by the addition of $\mathrm{HCl}$ up to a $15 \%$. Those two contributions (related to (100) Pt steps and terraces and wide 
domains) remarkably increase with the $\mathrm{HCl}$ concentration up to that $15 \%$. The increase of (100) sites up to that optimum $15 \%$ is counterbalanced with the diminution of the (110) and (111) signals although the latter is considerable weaker. For higher $\mathrm{HCl}$ amounts $(20 \% \mathrm{HCl})$, the $(100)$ quality is drastically affected. Thus, for the sample prepared in the presence of a $20 \% \mathrm{HCl}$, the peaks corresponding to the $(100)$ contributions decrease in intensity while the (110)-site related signal increases, thus confirming the loss of quality concerning the (100) preferential orientation. It is important to highlight that the $(100)$ quality of the $15 \% \mathrm{HCl}-$ modified Pt nanoparticles is significantly better that that previously obtained in the presence of $25 \% \mathrm{HCl}$ using $\mathrm{H}_{2} \mathrm{PtCl}_{6}$ as platinum precursor [10c] and with a significant lower amount of surface modifier.

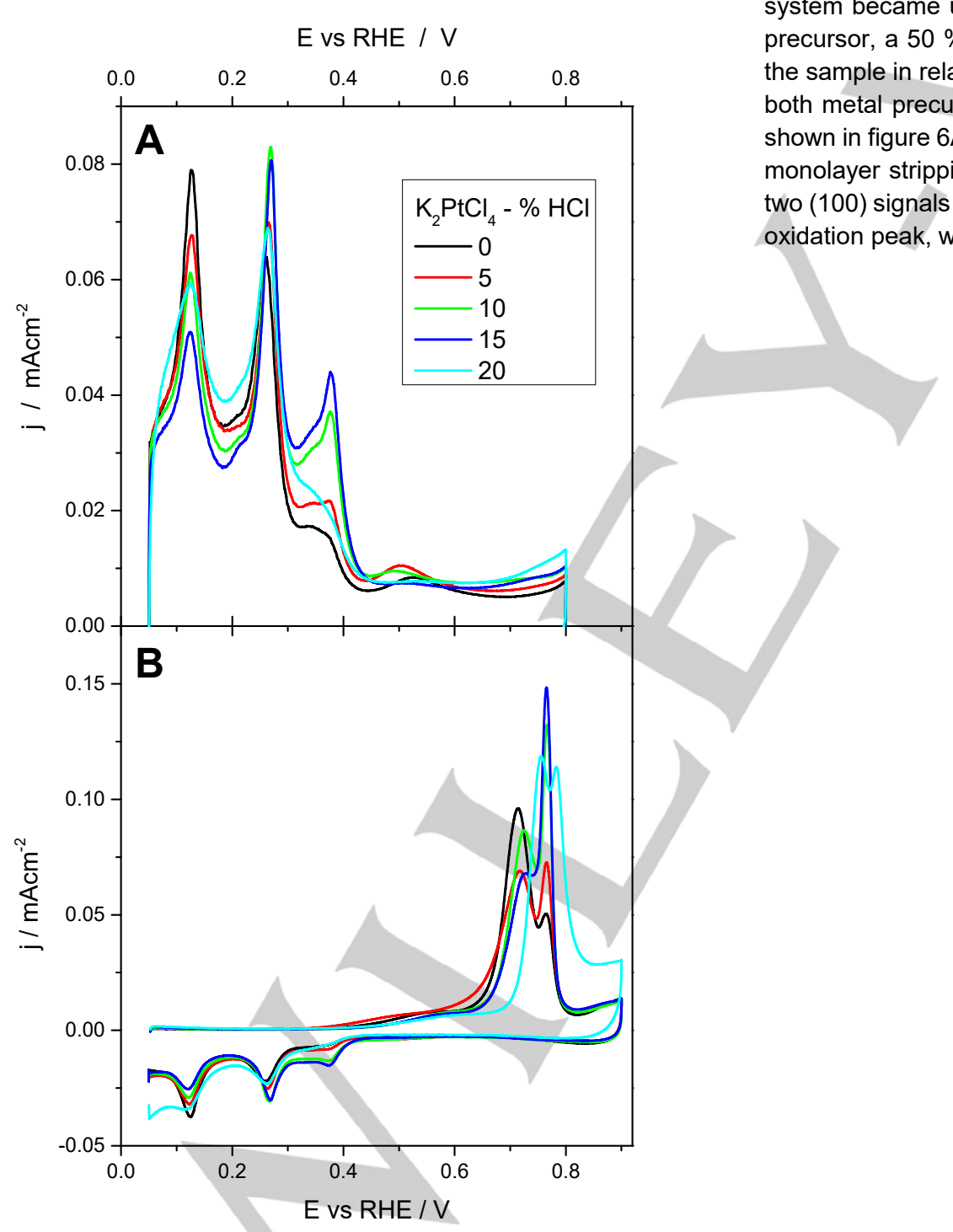

Similarly, the CO stripping on these nanoparticles (showed in Figure 5B) although less sensitive, also confirms those previous results. The relative decrease of the peak centered at $0.73 \mathrm{~V}$ and the consecutive increase of the sharp peak at $0.78 \mathrm{~V}$ vs RHE clearly highlights the increase of the Pt (100) terraces sites and wide domains for the samples prepared using $\mathrm{K}_{2} \mathrm{PtCl}_{4}$ as platinum source and with $\mathrm{HCl}$ up to $15 \%$.

The use of $\mathrm{H}_{2} \mathrm{SO}_{4}$ as surface modifier also denotes a relative change in the surface structure of the $\mathrm{Pt}$ nanoparticles using $\mathrm{K}_{2} \mathrm{PtCl}_{4}$ as $\mathrm{Pt}$ precursor (figure 6). Previous results for $\mathrm{H}_{2} \mathrm{SO}_{4}$ modified $\mathrm{Pt}$ nanoparticles using $\mathrm{H}_{2} \mathrm{PtCl}_{6}$ as modifier showed that the synthesis was very sensitive to the amount of modifier added, and that the amount of (100) sites progressively grows with the acid concentration. The maximum was obtained for a $25 \%$ (in volume) $\mathrm{H}_{2} \mathrm{SO}_{4}$, which corresponds to a $38 \% \mathrm{w} / \mathrm{w}$, before the system became unstable. In the case of using $\mathrm{K}_{2} \mathrm{PtCl}_{4}$ as metal precursor, a $50 \% \mathrm{H}_{2} \mathrm{SO}_{4}$ could be reached, being the quality of mple in relation to the amount of (100) sites very similar for both metal precursors at the best mentioned concentrations, as shown in figure $6 \mathrm{~A}$ and reference [10b]). Figure $6 \mathrm{~B}$ shows the $\mathrm{CO}$ monolayer stripping voltammograms for which the growth of the two (100) signals in figure $6 \mathrm{~A}$ can be followed with the second $\mathrm{CO}$ oxidation peak, which is centered at $0.75 \mathrm{~V}$.

Figure 5. (A) Voltammetric profiles of the Pt nanoparticles using $\mathrm{K}_{2} \mathrm{PtCl}_{4}$ as $\mathrm{Pt}$ precursor in the presence of different $\mathrm{HCl}$ percentages. Scan rate $50 \mathrm{mVs}^{-1}$. (B) $\mathrm{CO}$ monolayer oxidation. Scan rate $20 \mathrm{mVs}^{-1}$. Test solution $0.5 \mathrm{M} \mathrm{H}_{2} \mathrm{SO}_{4}$. 


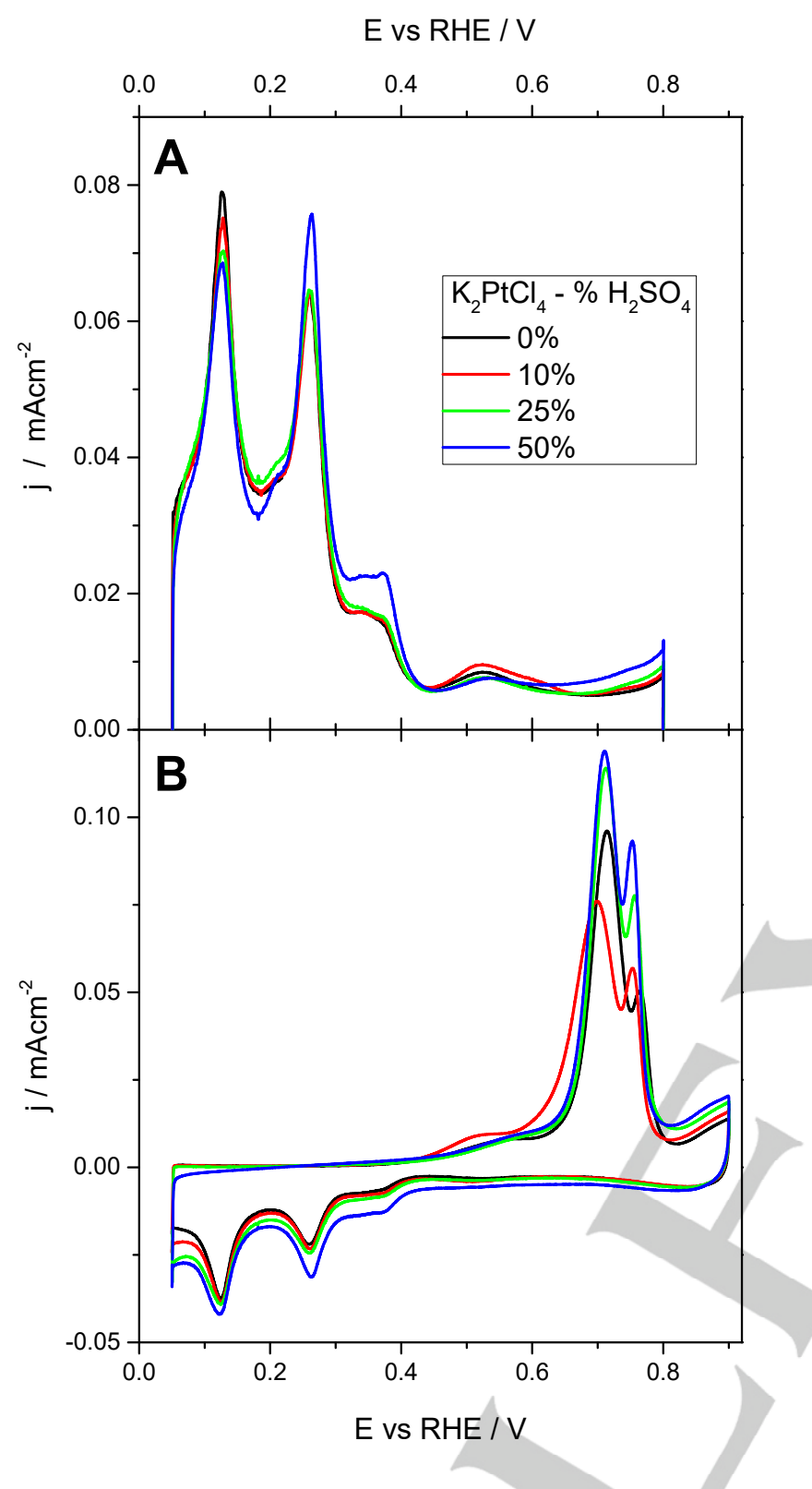

Figure 6. (A) Voltammetric profile of the Pt nanoparticles synthesized using $\mathrm{H}_{2} \mathrm{SO}_{4}$ at different concentrations. Scan rate $50 \mathrm{mVs}^{-1}$. (B) $\mathrm{CO}$ monolayer oxidation at $20 \mathrm{mVs}^{-1}$. Test solution $0.5 \mathrm{M} \mathrm{H}_{2} \mathrm{SO}_{4}$

So far we have qualitatively analysed the amount of (100) sites. Nevertheless, the amount of this type of site can be conveniently quantitatively measured through germanium irreversible adsorption as described in previous contributions [13, 26]. Briefly, the glassy carbon electrode with the platinum nanoparticles attached was transferred with a drop of a $10^{-2} \mathrm{M} \mathrm{GeO}_{2}$ and $1 \mathrm{M}$ $\mathrm{NaOH}$ solution into an electrochemical cell with $0.5 \mathrm{M} \mathrm{H}_{2} \mathrm{SO}_{4}$. The contact with the solution was performed at controlled potential, $0.1 \mathrm{~V}$ vs RHE. From the voltammogram obtained, the area due to the germanium contribution was obtained by integration and from that area, the (100)-site percentage could be obtained by using the calibration expression found in literature, which was obtained with model surfaces (single crystals) [26].

Table 1 presents the values obtained for the quantification of (100) sites, given in percentages, for the most preferentially oriented samples according to their cyclic voltammograms in $\mathrm{H}_{2} \mathrm{SO}_{4}$. In addition, the data for the $\mathrm{HCl}$ and $\mathrm{H}_{2} \mathrm{SO}_{4}$ modified $\mathrm{Pt}$ nanoparticles prepared with $\mathrm{H}_{2} \mathrm{PtCl}_{6}$ as metal precursor and reported previously [10b, 10c] are also included.

Table 1. Relative percentage of (100) sites measured by $\mathrm{Ge}$ irreversible adsorption for different additives in the aqueous phase of water-in-oil microemulsion

Additive $\%(100)$ sites

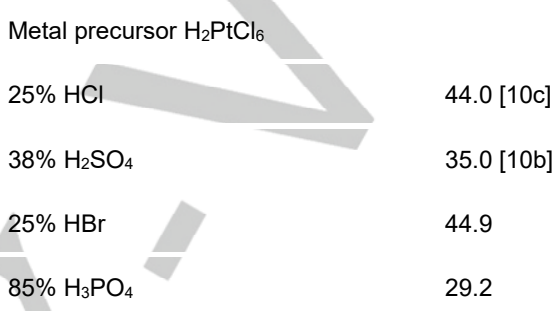

Metal precursor $\mathrm{K}_{2} \mathrm{PtCl}_{4}$

$15 \% \mathrm{HCl}$

46.7

From the results shown in table 1 , it is confirmed that the nanoparticles with the highest amount of (100) sites are those prepared using $\mathrm{K}_{2} \mathrm{PtCl}_{4}$ as metal precursor and a $15 \% \mathrm{HCl}$ as surface modifier. This result was somehow expected from the voltammograms in $\mathrm{H}_{2} \mathrm{SO}_{4}$ shown previously and particularly, from the contribution located at $0.37 \mathrm{~V}$, for which this sample showed the largest and most defined peak. All the samples prepared in the presence of $\mathrm{K}_{2} \mathrm{PtCl}_{4}$ and $\mathrm{HCl}$ were analyzed with this $\mathrm{Ge}$ quantification method and a volcano shape curve similar to that reported previously [10c] was obtained when comparing the amount of $(100)$ sites with the $\mathrm{HCl}$ percentage. Thus, percentages of $18.6,19.1,40.8,46.7$ and $28.9 \%$ sites with (100) geometry were obtained for non-modified and $5,10,15$ and $20 \% \mathrm{HCl}$ with $\mathrm{K}_{2} \mathrm{PtCl}_{4}$ as metal precursor (result not shown).

In parallel, all samples were also analysed by TEM. Although CV gives a complete behavior of the sample and the response is a direct reflect of all surface sites present at the surface of the nanoparticles, TEM also gives qualitative information concerning the quality of the sample. Thus, samples displaying a high amount of (100) sites are expected to be preferentially cubic, as a cube is ideally enclosed by $6(100)$ faces. TEM analysis of the samples was not an easy task. TEM grids were prepared collecting the samples before adding acetone, which causes phase separation and makes the nanoparticles precipitate and then agglomerate. This agglomeration has to be avoided in order to obtain high quality TEM images. Unfortunately, the acids used as surface 
modifiers are in such a high concentration in many of the samples that the grid is damaged during the TEM sample preparation. In some of the cases the sample cannot be analyzed due to this problem and in others, small grey dots that look like quasi spherical nanoparticles are clearly observed. EDX experiments confirmed that those grey dots were not platinum.

Figure 7 shows some representative TEM figures obtained for some of the samples of interest. Figure 7A shows the quasi spherical shape of HI-modified nanoparticles synthesized using $\mathrm{H}_{2} \mathrm{PtCl}_{6}$ as metal precursor. As deduced from the voltammogram CVs shown in figure 2, the presence of $\mathrm{HI}$ does not originate any preferential orientation and the mean size is smaller. On the other hand, figures 7B, 7C and 7D show the cubic shapes obtained with $10 \% \mathrm{HBr}$ and $15 \% \mathrm{HCl}$-modified platinum nanoparticles prepared using $\mathrm{H}_{2} \mathrm{PtCl}_{6}$ and $\mathrm{K}_{2} \mathrm{PtCl}_{4}$, respectively, as metal precursor. As it is observed, both samples show good quality cubes, but voltammograms shown in figure 1 and figure 5 make clear that the latter are better (100) preferentially oriented. In addition, in figure 7D the previously mentioned problem concerning the sample preparation for acid-rich samples is observed, especially at the top of the image as small grey dots that without any EDX analysis could be taken as much smaller Pt nanoparticles without any preferential orientation. An explanation for the higher amount of (100) terrace sites could be also justified considering the particle size of the nanoparticles. In fact the larger the nanoparticles, the wider can be the (100) surface domains. In fact $\mathrm{H}_{2} \mathrm{SO}_{4}$ and $\mathrm{HCl}$ modified nanoparticles obtained from $\mathrm{H}_{2} \mathrm{PtCl}_{6}$ and $\mathrm{HCl}$ modified nanoparticles from $\mathrm{K}_{2} \mathrm{PtCl}_{4}$ have a mean particle size of about $9,12-14$ and $17 \mathrm{~nm}$, respectively.

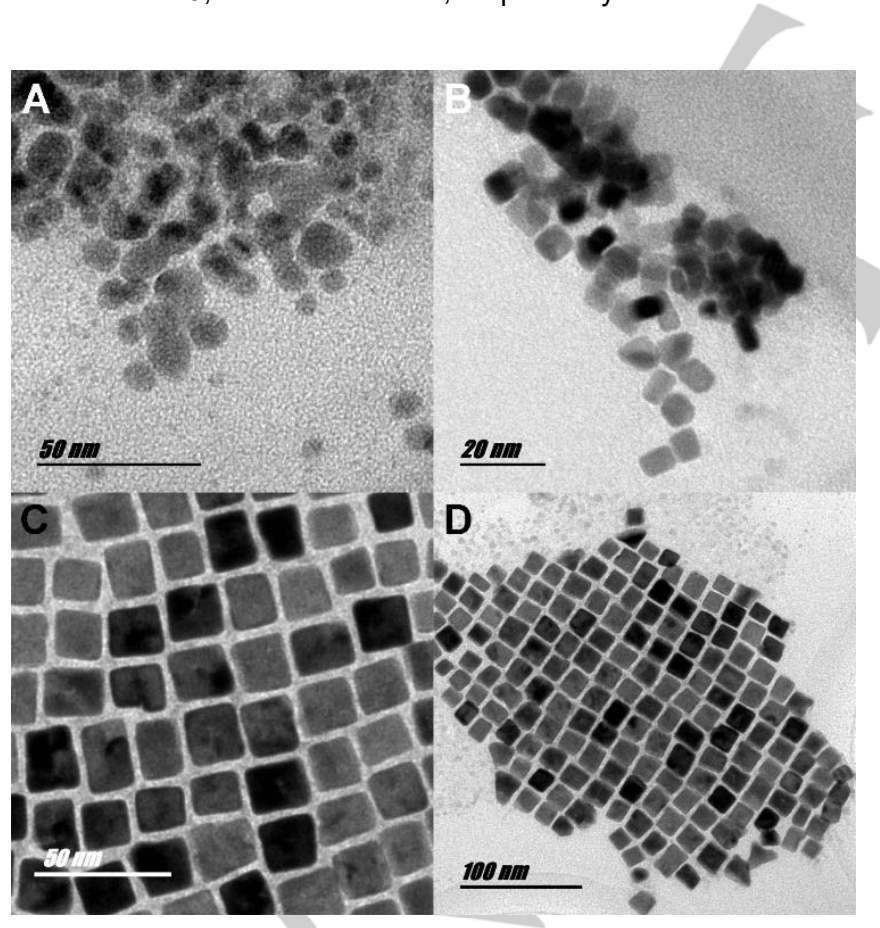

Figure 7. Pt nanoparticles synthesized using w/o microemulsion with $\mathrm{H}_{2} \mathrm{PtCl}_{6}$ as metal precursor prepared in the presence of $(\mathrm{A}) 2.5 \% \mathrm{HI}$, (B) $10 \% \mathrm{HBr}$ and (C) and (D) using $\mathrm{K}_{2} \mathrm{PtCl}_{4}$ as metal precursor with $15 \% \mathrm{HCl}$.
The present results point out that we can prepare preferentially oriented cubic nanoparticles with a high yield using some acids as surface modifiers. The importance of preparing this type of catalysts lies in the fact that many electrochemical reactions of high interest are structure sensitive, so these cubic nanoparticles could be chosen as better catalysts for electrochemical reactions in which (100) sites are favorable. Ammonia electrooxidation is one of the most structure sensitive reactions which takes place almost exclusively on (100) sites [3b, 3c]. In fact, this reaction is so sensitive that it can also be used as a tool to get information about the quality and amount of (100) sites [10c]. For this study, the nanoparticles containing a high amount of (100) sites, were used as electrocatalysts and the results are given in figure 8 . For sake of comparison, the data corresponding to quasi-spherical nanoparticles ( $\mathrm{HI}$ modified) which give the lowest current densities, are also shown. As it is observed, the $\mathrm{Pt}$ nanoparticles synthesized using $\mathrm{K}_{2} \mathrm{PtCl}_{4}$ as metal precursor and using a $15 \%$ $\mathrm{HCl}$ as surface modifier displayed the best catalytic activity for ammonia oxidation in terms of peak current density. This result was expected from the $\mathrm{Ge}$ data (table 1), for which this catalyst was the one with the highest (100) percentage. In addition, the data for $25 \% \mathrm{HBr}, 25 \% \mathrm{HCl}$ and $47 \% \mathrm{H}_{2} \mathrm{SO}_{4}$-modified platinum nanoparticles are also very satisfactory.

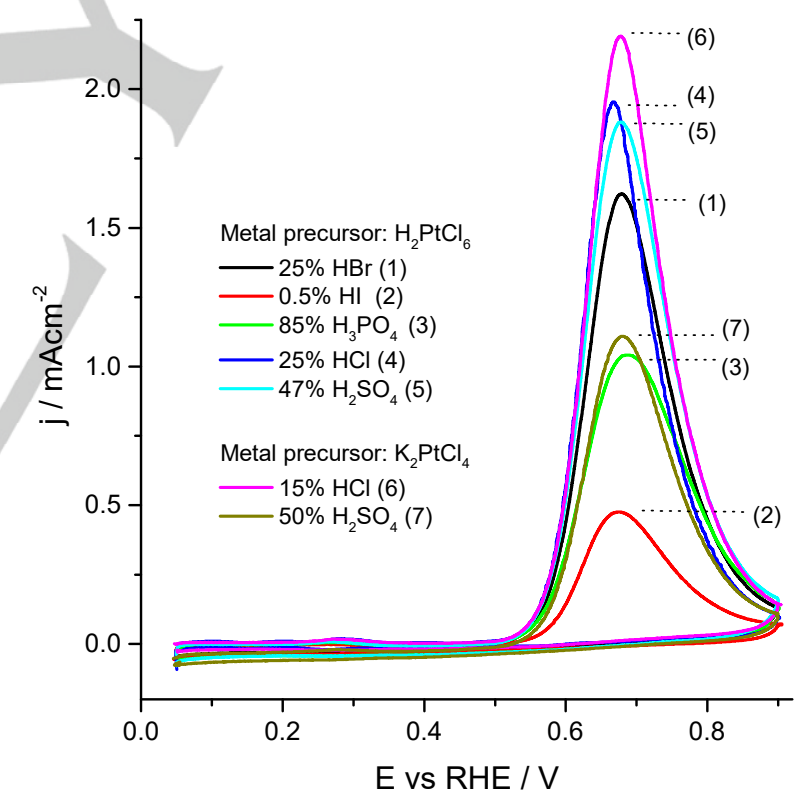

Figure 8. Voltammetric profiles for ammonia electrooxidation for different $\mathrm{Pt}$ nanoparticles synthesized using different acid concentrations in the aqueous phase of the w/o microemulsion and different metal precursors. Scan rate 10 $\mathrm{mV} \mathrm{s}{ }^{-1}$. Test solution: $0.2 \mathrm{M} \mathrm{NaOH}+0.1 \mathrm{M} \mathrm{NH}_{3}$. 


\section{Conclusions}

Pt nanoparticles with preferential shapes were synthesized using different acids and using different Pt precursors in water-in-oil microemulsions. On the one hand, the effect of different inorganic acids was analysed. First of all, several hydrogen halides were used. Specifically, $\mathrm{HBr}$ and $\mathrm{HI}$ were used and compared with the effect of $\mathrm{HCl}$, which had been already studied in a previous publication [10c]. $\mathrm{HBr}$, as in the case of $\mathrm{HCl}$, gave nanoparticles with a high proportion of (100) sites and showed a preferential cubic shape as observed by TEM. On the contrary HI-modified Pt nanoparticles did not show a preferential surface structure and their $\mathrm{CV}$ in $\mathrm{H}_{2} \mathrm{SO}_{4}$ solution is characteristic of a polyoriented surface. In addition, $\mathrm{H}_{2} \mathrm{SO}_{4}$, had also been used previously as a successful modifier toward the synthesis of preferentially oriented cubic nanoparticles [10b]. In this manuscript, the effect of a weaker multiprotic acid, $\mathrm{H}_{3} \mathrm{PO}_{4}$, was also evaluated, yielding nanoparticles with a slightly higher percentage of (100) sites than a polyoriented surface but poorer results than in the case of $\mathrm{H}_{2} \mathrm{SO}_{4}$.

On the other hand, some organic modifiers were used in order to obtain (111)-rich nanoparticles. Similar organic molecules had been successfully used for synthesising (111)-rich palladium nanoparticles, although not in microemulsion. For this purpose citric, ascorbic and oxalic acids were used as modifiers. Although an increase in the number of (111) sites was accomplished, this improvement was quite subtle.

Finally, the nature of the Pt source was also explored. Thus, the metal precursor $\mathrm{H}_{2} \mathrm{PtCl}_{6}$ used for the previous experiments was replaced by $\mathrm{K}_{2} \mathrm{PtCl}_{4}$ and employed together with those modifiers giving the best results $\left(\mathrm{HCl}\right.$ and $\left.\mathrm{H}_{2} \mathrm{SO}_{4}\right)$. Although the latter did not significantly improve the results obtained with the $\mathrm{H}_{2} \mathrm{PtCl}_{6}$ as metal precursor, $\mathrm{HCl}$ yielded very well defined cubic nanoparticles, with the highest (100) percentage among those obtained with this methodology with the different used modifiers. Finally, the nanoparticles having the highest amounts of (100) sites were tested towards ammonia electrooxidation and, as expected, the highest peak current density was obtained with the $15 \% \mathrm{HCl}$ modified $\mathrm{Pt}$ nanoparticles prepared with $\mathrm{K}_{2} \mathrm{PtCl}_{4}$ as metal precursor.

\section{Experimental Section}

Pt nanoparticles were synthesized in a similar methodology to that previously reported [10c], using a w/o microemulsion of water/polyethylene glycol dodecyl ether (Brij®L4, Sigma-Aldrich)/n-heptane (99.86\% p.a. from Acros Organics) with a volume percentage of $3,16.5$ and $80.5 \%$, respectively. In the water phase the metal precursor (constant $0.1 \mathrm{M}$ concentration) together with the surface modifier were added. In this manuscript, two different $\mathrm{Pt}$ precursors have been used, $\mathrm{H}_{2} \mathrm{PtCl}_{6}(40 \%$ weight Pt Acros Organics) and $\mathrm{K}_{2} \mathrm{PtCl}_{4}$ (99.99\% Acros Organics). The different modifiers that have been used are the following: hydrochloric acid ( $\mathrm{HCl} 37 \%$ p.a. from Panreac), sulfuric acid $\left(\mathrm{H}_{2} \mathrm{SO}_{4} 95-97 \%\right.$, p.a. from Merck), bromhydric acid ( $\mathrm{HBr} 48 \%$ ACS reagent from Acros Organics), iodhydric acid (HI 57\% from Sigma Aldrich) phosphoric acid $\left(\mathrm{H}_{3} \mathrm{PO}_{4} 85 \%\right.$, p.a. from Merck), citric acid (99.7\% from Prolabo), ascorbic acid (reagent grade from Sigma-Aldrich) and oxalic acid $\left((\mathrm{COOH})_{2} \times 2 \mathrm{H}_{2} \mathrm{O}\right.$ ACS, ISO, Reagent) from Merck. Once the microemulsion was prepared and ultrasonically mixed, $\mathrm{NaBH}_{4}$ (Reagent Plus $99 \%$ from Sigma Aldrich) as solid was added as reducing agent. The amount of the reducing agent was that necessary for a $1 \mathrm{M}$ concentration in the water phase. The complete reduction usually takes place in a couple of minutes in the absence of any surface modifier. Nevertheless, in the presence of the modifiers, the process could take up to 8 minutes to make the micellar solution become black. Thirty minutes after the reducing agent was added, acetone was added to the solution to cause phase separation. Once the nanoparticles precipitated, they were washed several times with acetone and ultrapure water (Millipore, $18.2 \mathrm{M} \Omega \mathrm{cm}$ ) in order to remove the modifiers and the surfactant. Finally, the nanoparticles were stored in ultrapure water as a suspension. The concentration of the different modifiers was limited to the as-purchased reagent concentration except when the nature and high acid concentration of the acid cause instability of the micellar solution. For example, in the case of $\mathrm{HBr}$ the concentrations varied from $0 \%$ (pure water) to $48 \%$ (commercial solution). However, for $\mathrm{HI}$ the maximum concentration used in the water phase was $10 \%$. Concentrations of the modifiers throughout the manuscript are expressed in $w / w \%$.

Surface characterisation of the nanoparticles was performed by Transmission Electron Microscopy (TEM). TEM allowed the shape and the size distribution of the samples to be estimated. These experiments were performed with a JEOL, JEM-2010, working at $200 \mathrm{kV}$. Electrochemical measurements were performed using a three-electrode electrochemical cell using a VMP3 multichannel potentiostat (BioLogic) with a NStat configuration (1 counter electrode, 1 reference electrode and up to 8 working electrodes working simultaneously). The counter electrode was a platinum wire and the reference electrode was a reversible hydrogen electrode (RHE) connected to the cell through a Luggin capillary. Gold collector electrodes, on which the nanoparticles were deposited, were used as working electrodes. Before each experiment, the working electrode was mechanically polished with alumina and rinsed with ultrapure water to eliminate the impurities. After checking the cleanness of the gold surface, a drop $(\approx 5 \mu \mathrm{l})$ was dropcasted on the surface and dried in an argon atmosphere. The active surface area of the Pt NPs was determined by the charge involved in the so-called hydrogen UPD region (between $0.06 \mathrm{~V}-0.6 \mathrm{~V}$ ) after the substraction of the double layer charging contribution and using the value of $230 \mu \mathrm{C} \mathrm{cm}^{-2}$ [27].

\section{Acknowledgements}

This work has been financially supported by the Ministerio de Economía y Competitividad (projects CTQ2013-44083-P and CTQ2013-48280-C3-3-R) and Generalitat Valenciana (project PROMETEOII/2014/013 and Beca Santiago Grisolía).

Keywords: electrocatalysis $•$ microemulsion $•$ nanoparticles • platinum • shape

[1] a) J. Solla-Gullon, F. J. Vidal-Iglesias, J. M. Feliu, Annu. Rep. Prog. Chem., Sect. C 2011, 107, 263-297; b) M. T. M. Koper, Nanoscale 2011, 3, $2054-$ 2073; c) F. J. V.-I. J. Solla-Gullón, E. Herrero, J. M. Feliu, A. Aldaz, in Polymer Electrolyte Fuel Cells: Science, Applications, and Challenges (Ed.: A. A. Franco), Pan Stanford Publishing Pte Ltd, Boca Raton, Florida, 2013, pp 93-52; d) Y. Bing, H. Liu, L. Zhang, D. Ghosh, J. Zhang, Chem. Soc. Rev. 2010, 39, 2184-2202; e) Z. Peng, H. Yang, Nano Today 2009, 4, 143-164; f) J. Chen, B. Lim, E. P. Lee, Y. Xia, Nano Today 2009, 4, 81-95; g) H. You, S. Yang, B. Ding, H. Yang, Chem. Soc. Rev. 2013, 42, 2880-2904.

[2] a) K. J. J. Mayrhofer, M. Arenz, B. B. Blizanac, V. Stamenkovic, P. N. Ross, N. M. Markovic, Electrochim. Acta 2005, 50, 5144-5154; b) S. Brimaud, S. Pronier, C. Coutanceau, J. M. Léger, Electrochem. Commun. 2008, 10, 17031707; c) J. Solla-Gullón, F. J. Vidal-Iglesias, E. Herrero, J. M. Feliu, A. Aldaz, Electrochem. Commun. 2006, 8, 189-194. 
[3] a) V. Rosca, M. T. M. Koper, Phys. Chem. Chem. Phys. 2006, 8, 2513-2524; b) F. J. Vidal-Iglesias, J. Solla-Gullón, V. Montiel, J. M. Feliu, A. Aldaz, J. Phys. Chem. B 2005, 109, 12914-12919; c) F. J. Vidal-Iglesias, N. GarciaAraez, V. Montiel, J. M. Feliu, A. Aldaz, Electrochem. Commun. 2003, 5, $22-$ 26.

[4] a) A. V. Tripkovic, S. L. J. Gojkovic, K. D. Popovic, J. D. Lovic, J. Serb. Chem. Soc. 2006, 71, 1333-1343; b) J. Solla-Gullón, F. J. Vidal-Iglesias, A. López-Cudero, E. Garnier, J. M. Feliu, A. Aldaz, Phys. Chem. Chem. Phys. 2008, 10, 3689-3698; c) S. B. Han, Y. J. Song, J. M. Lee, J. Y. Kim, K. W. Park, Electrochem. Commun. 2008, 10, 1044-1047.

[5] C. Buso-Rogero, V. Grozovski, F. J. Vidal-Iglesias, J. Solla-Gullon, E. Herrero, J. M. Feliu, J. Mater. Chem. A 2013, 1, 7068-7076.

[6] C. Wang, H. Daimon, Y. Lee, J. Kim, S. Sun, J. Am. Chem. Soc. 2007, 129, 6974-6975

[7] a) C. M. Sanchez-Sanchez, J. Solla-Gullon, F. J. Vidal-Iglesias, A. Aldaz, V. Montiel, E. Herrero, J. Am. Chem. Soc. 2010, 132, 5622-5624; b) A. Wieckowski, Interfacial electrochemistry : theory, experiment, and applications, Marcel Dekker, New York, 1999; c) N. M. Markovic, H. A. Gasteiger, P. N. Ross, J. Phys. Chem. 1995, 99, 3411-3415; d) A. A. Gewirth, M. S. Thorum, Inorg. Chem. 2010, 49, 3557-3566; e) R. R. Adzic, in Electrocatalysis (Eds.: J. Lipkowski, P. N. Ross), Wiley-VCH, New York 1998, pp. 197-242; f) A. M. Gomez-Marin, R. Rizo, J. M. Feliu, Catal. Sci. Technol. 2014, 4, 1685-1698; g) A. Kuzume, E. Herrero, J. M. Feliu, J. Electroanal. Chem. 2007, 599, 333-343; h) A. S. Bandarenka, H. A. Hansen, J. Rossmeisl, I. E. L. Stephens, Phys. Chem. Chem. Phys. 2014, 16, 1362513629; i) M. D. Maciá, J. M. Campina, E. Herrero, J. M. Feliu, J. Electroanal. Chem. 2004, 564, 141-150.

[8] a) M. Duca, M. C. Figueiredo, V. Climent, P. Rodriguez, J. M. Feliu, M. T. M. Koper, J. Am. Chem. Soc. 2011, 133, 10928-10939; b) M. Duca, M. O. Cucarella, P. Rodriguez, M. T. M. Koper, J. Am. Chem. Soc. 2010, 132, 18042-18044; c) M. Duca, P. Rodriguez, A. I. Yanson, M. T. M. Koper, Top. Catal. 2014, 57, 255-264.

[9] J. Solla-Gullón, F. J. Vidal-Iglesias, P. Rodríguez, E. Herrero, J. M. Feliu, J. Clavilier, A. Aldaz, J. Phys. Chem. B 2004, 108, 13573-13575.

[10] a) F. J. Vidal-Iglesias, J. Solla-Gullón, P. Rodríguez, E. Herrero, V. Montiel, J. M. Feliu, A. Aldaz, Electrochem. Commun. 2004, 6, 1080-1084; b) R. A. Martínez-Rodríguez, F. J. Vidal-Iglesias, J. Solla-Gullón, C. R. Cabrera, J. M. Feliu, ChemPhysChem 2014, 15, 1997-2001; c) R. A. Martínez-Rodríguez, F. J. Vidal-Iglesias, J. Solla-Gullon, C. R. Cabrera, J. M. Feliu, J. Am. Chem. Soc. 2014, 136, 1280-1283.

[11] C. Susut, Y. Tong, Electrocatalysis 2011, 2, 75-81.

[12] a) H. Song, F. Kim, S. Connor, G. A. Somorjai, P. Yang, J. Phys. Chem. B 2005, 109, 188-193; b) C.-Y. Chiu, Y. Li, L. Ruan, X. Ye, C. B. Murray, Y. Huang, Nat Chem 2011, 3, 393-399; c) T. S. Ahmadi, Z. L. Wang, T. C. Green, A. Henglein, M. A. El-Sayed, Science 1996, 272, 1924-1926.

[13] J. Solla-Gullón, P. Rodríguez, E. Herrero, A. Aldaz, J. M. Feliu, Phys. Chem Chem. Phys. 2008, 10, 1359-1373.

[14] F. J. Vidal-Iglesias, J. Solla-Gullón, E. Herrero, V. Montiel, A. Aldaz, J. M. Feliu, Electrochem. Commun. 2011, 13, 502-505.

[15] L. C. Gontard, L. Y. Chang, C. J. D. Hetherington, A. I. Kirkland, D. Ozkaya, R. E. Dunin-Borkowski, Angew. Chem. Int. Ed. 2007, 46, 3683-3685.
[16] Y. Xiong, H. Cai, B. J. Wiley, J. Wang, M. J. Kim, Y. Xia, J. Am. Chem. Soc. 2007, 129, 3665-3675.

[17] a) B. Lim, H. Kobayashi, P. H. C. Camargo, L. F. Allard, J. Liu, Y. Xia, Nano Res. 2010, 3, 180-188; b) M. Jin, H. Liu, H. Zhang, Z. Xie, J. Liu, Y. Xia, Nano Res. 2011, 4, 83-91.

[18] C.-D. Xu, J.-Y. Ye, L. Chen, D.-H. Chen, J.-T. Li, C.-H. Zhen, S.-G. Sun, Electrochim. Acta 2015, 162, 129-137.

[19] B. Wu, N. Zheng, Nano Today 2013, 8, 168-197.

[20] a) M. P. Soriaga, J. A. Schimpf, A. Carrasquillo, J. B. Abreu, W. Temesghen, R. J. Barriga, J. J. Jeng, K. Sashikata, K. Itaya, Surf. Sci. 1995, 335, 273-280; b) A. Carrasquillo Jr, J.-J. Jeng, R. J. Barriga, W. F. Temesghen, M. P. Soriaga, Inorg. Chim. Acta 1997, 255, 249-254.

[21] C.-Y. Chiu, H. Wu, Z. Yao, F. Zhou, H. Zhang, V. Ozolins, Y. Huang, J. Am. Chem. Soc. 2013, 135, 15489-15500.

[22] L. Ruan, H. Ramezani-Dakhel, C.-Y. Chiu, E. Zhu, Y. Li, H. Heinz, Y. Huang, Nano Lett. 2013, 13, 840-846.

[23] B. Lim, Y. Xiong, Y. Xia, Angew. Chem. Int. Ed. 2007, 46, 9279-9282.

[24] a) M. Shao, T. Yu, J. H. Odell, M. Jin, Y. Xia, Chem. Commun. 2011, 47, 6566-6568; b) Y. Xiong, Y. Xia, Adv. Mater. (Weinheim, Ger.) 2007, 19 3385-3391; c) B. Lim, M. Jiang, J. Tao, P. H. C. Camargo, Y. Zhu, Y. Xia, Adv. Funct. Mater. 2009, 19, 189-200.

[25] J. Yue, Z. Du, M. Shao, Chem. Phys. Lett. 2016, 659, 159-163.

[26] P. Rodríguez, E. Herrero, J. Solla-Gullón, F. J. Vidal-Iglesias, A. Aldaz, J. M. Feliu, Electrochim. Acta 2005, 50, 3111-3121.

[27] Q. S. Chen, J. Solla-Gullon, S. G. Sun, J. M. Feliu, Electrochim. Acta 2010, 55, 7982-7994.

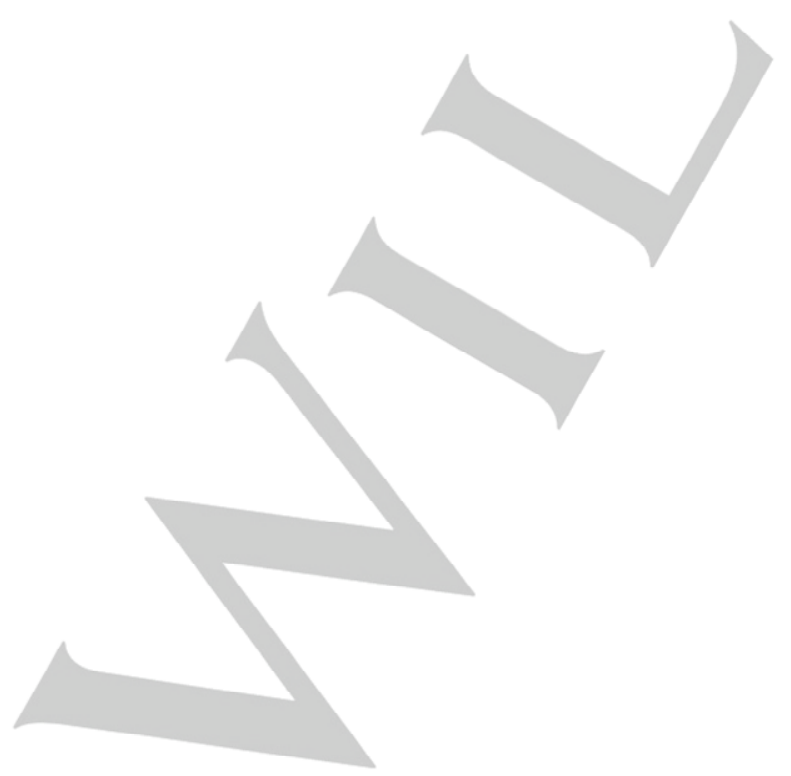


Entry for the Table of Contents (Please choose one layout)

Layout 1:

\section{ARTICLE}

The electrochemical characterisation of $\mathrm{Pt}$ nanoparticles prepared in waterin-oil microemulsions in the presence of different surface modifiers is performed. Well defined cubic nanoparticles with a preferential (100) surface structure are obtained and tested for different electrocatalytic reactions.

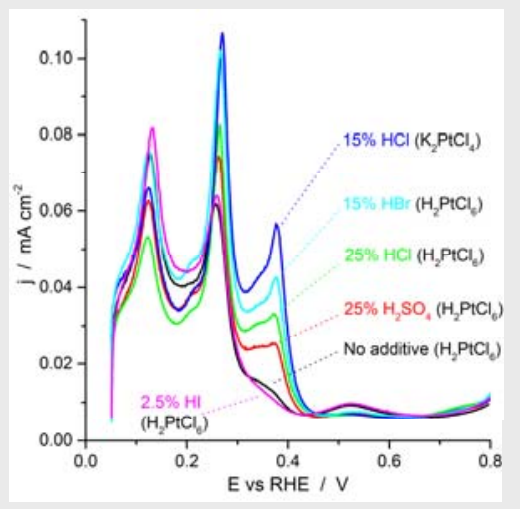

Roberto A. Martínez-Rodríguez,

Francisco J. Vidal-Iglesias, José SollaGullón, Carlos R. Cabrera and Juan M. Feliu*

Page No. - Page No.

Electrochemical characterization of platinum nanoparticles prepared in water-in-oil microemulsion in the presence of different modifiers and metal precursors 